\title{
Role of the Caribbean low-level jet and the Choco jet in the patterns of atmospheric moisture transport towards Central America
}

\author{
José S. Morales 1, Paola A. Arias 1, J. Alejandro Martínez 2,* \\ Published: 08/11/2017 \\ Academic Editor: Ana María Durán-Quesada \\ 1 Grupo de Ingeniería y Gestión Ambiental (GIGA), Facultad de Ingeniería, Universidad de Antioquia; \\ jsebastian.morales@udea.edu.co,paola.arias@udea.edu.co \\ 2 Escuela Ambiental, Facultad de Ingeniería, Universidad de Antioquia; john.martinez@udea.edu.co \\ * Correspondence: jsebastian.morales@udea.edu.co; Tel.: +57-219-55-71
}

\begin{abstract}
The Dynamic Recycling Model (DRM) is used to analyze the seasonal patterns of water vapor transport to Central America (CAM) and their interannual variability, with special emphasis on the role of the Caribbean low-level jet (CLLJ) and the Choco jet (CJ) during the period 1980-2012, using information from the ERA-Interim reanalysis. Our results suggest that approximately $35 \%$ of mean annual atmospheric moisture transported to CAM comes from the Caribbean Sea. This transport is closely related to the CLLJ, showing that a strong (weak) jet induces a greater (smaller) transport from the Atlantic to CAM. On the other hand, transport from the Pacific exhibits a marked seasonality, responding to the intensity of the $\mathrm{CJ}$, which during high intensity episodes stimulates an increase in transport of water vapor. Finally, a comparison of our results with the work by DuránQuesada et al. (2017) using the 3D FLEXPART model, suggests that the DRM (which is 2D) has a bias in estimating the mean annual cycle of water vapor transport associated with the CLLJ wind shear. However, the DRM is able to capture the interannual variability of the moisture transport and its response to the El NiñoSouthern Oscillation (ENSO) and low-level jets anomalies.
\end{abstract}

Keywords: Choco low-level jet, Caribbean low-level jet, Central America climate, Moisture transport, ENSO.

\section{Introduction}

Central America (CAM) is a thin strip of land, surrounded by ocean masses. It is located in the tropical zone, where high energy availability drives fundamental processes that determine the regional climate. Among these processes are evaporation, which induce the increase of the amount of water vapor in the atmosphere. In addition, various processes linked to atmospheric dynamics, such as the development of the Caribbean and Choco lowlevel jets (CLLJ and CJ), are fundamental in the transport of water vapor from oceanic masses to continental masses [1,2,3,4]. Duran-Quesada et al. [1], not only identified the major sources of atmospheric moisture to CAM, but also perform a spatial analysis of the influence of low level jets on precipitation in the region and its interannual variability associated with phenomena such as El Niño-Southern Oscillation (ENSO), finding a strong response of moisture transport patterns to this phenomenon. Other factors that strongly influence the climate of the zone are the presence of the North Atlantic Subtropical High, changes in sea surface temperature, the intertropical convergence zone and the Central American topography [5].

The climatic characteristics in the region are crucial for the development of the Central American countries, given 
The 1st International Electronic Conference on Hydrological Cycle (CHyCle-2017), 12 - 16 November 2017;

Sciforum Electronic Conference Series, Vol. 1, 2017

that the main engine of the economy is the primary sector, including agriculture, one of the activities on which most people from low socio-economic status depend. The crop vulnerability to extreme events is high, especially during drought, which put at risk the food security of a large part of the population, mainly in countries like Guatemala, El Salvador, Honduras and Nicaragua. On these countries is the Central American Dry Corridor, which besides representing a climatic phenomenon, defines a group of ecosystems that are combined in the dry tropical forest ecoregion [6]. Ecoregions characterized by low resilience face more intense extreme events [6].

This study aims to estimate the atmospheric moisture transported to CAM from different sources, to characterize the transport of atmospheric moisture into the region and to identify the possible changes observed in the transport patterns from these sources in the face of interannual climate variability events, such as ENSO.

\section{Data and Methodology}

In order to identify the major sources of atmospheric moisture to CAM, the Dynamic Recycling Model (DRM) was implemented. This is a semi-Lagrangian 2D model that estimates the exchange of water vapor from different sources, based on the principle of conservation of mass applied to a column of atmosphere under the assumption of a well-mixed atmosphere [7,8]. The DRM uses daily fields of evaporation, precipitation, precipitable water and vertically integrated moisture flux (VIMF) as input data. This fields are obtained from the ERA-Interim reanalysis, at a spatial resolution of $0.75^{\circ}$ from 1980 to 2012 [9]. Additional to these fields, the model uses a raster map in which the regions that exchange moisture are defined. The map used in this study (Figure 1) is obtained by making a modification of the map of regions used in the work by Agudelo et al. [10]. We consider 22 source subregions among which is our region of interest, CAM. Only those subregions identified as main contributors to CAM by Durán-Quesada et al. [1] when implementing the FLEXPART (3D) model are analyzed, in order to perform a comparison with the results obtained when implementing DRM.

It is worth noting that 2D models generally present problems in estimating the transport of water vapor [11,12], including biases associated with the presence of vertical wind shear. $\mathrm{Hu}$ and Dominguez [13] reported this problem for the DRM, showing that in a region with strong wind shear the VIMF does not capture the different origin of moisture at different vertical levels. In this study, monthly data of zonal wind speed and specific humidity at 800 and $200 \mathrm{hPa}$ from ERA-Interim reanalysis are used, with the purpose of performing an analysis of the vertical shear of the zonal wind in the vicinity of CAM.

Additionally, various indices are used to evaluate the relationship between moisture transport to CAM and some regional circulations. To quantify the intensity of the low-level jets, ERA-Interim data is used at a spatial resolution of $0.75^{\circ}$. The Caribbean jet index (ICLLJ) is calculated as a spatial average of the additive inverse of the anomalies of the zonal component of the wind at $925 \mathrm{hPa}$ over the region $12.5-17.5^{\circ} \mathrm{N}, 80-70{ }^{\circ} \mathrm{W}$, based on the methodology proposed by Wang [14]. The Choco jet index (ICJ) is similarly calculated as a zonal wind spatial average in the region $5^{\circ} \mathrm{S}-7.5^{\circ} \mathrm{N}, 80^{\circ} \mathrm{W}$, following Poveda and Mesa [15]. In the case of the ENSO, hydrological years are constructed using the corresponding ENSO years classification, carried out by the NOAA climate prediction center, through the Oceanic Niño Index (ONI), available on the website: http://origin.cpc.ncep.noaa.gov/products/analysis monitoring/ensostuff/ONI v5.php. Seven episodes for El Niño (1982-1983, 1986-1987, 1991-1992, 1997-1998, 2002-2003, 2004-2005, and 2009-2010) and seven episodes for La Niña (1984-1985, 1988-1989, 1998-1999, 1999-2000, 2007-2008, 2010-2011, and 2011-2012) were selected for further analysis. 
The 1st International Electronic Conference on Hydrological Cycle (CHyCle-2017), 12 - 16 November 2017;

Sciforum Electronic Conference Series, Vol. 1, 2017

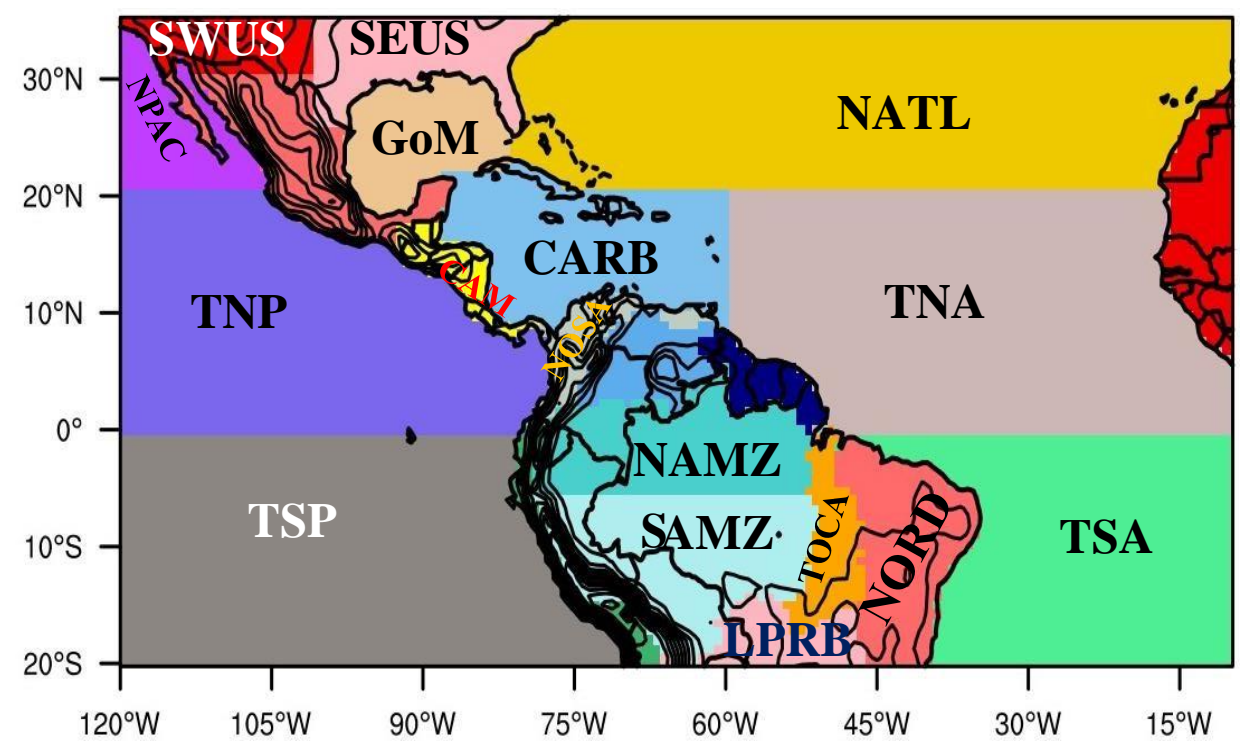

Figure 1. Region of study. Regions considered as possible moisture sources to Central America domain (CAM): NOSA "northern South America”, ORIC “Orinoco Region”, NPAC “Northern Pacific”, TNP “Tropical North Pacific", TSP "Tropical South Pacific", NATL "North Atlantic", TNA “Tropical North Atlantic", TSA “Tropical South Atlantic", GOM "Gulf of Mexico", CABN "Caribbean Sea", GUYN "Guyanas", PECH "Peru-Chile", NAMZ "Northern Amazon", SAMZ "Southern Amazon", TOCA “Tocantins river", NORD “Northeastern Brazil”, LPRB “La Plata River Basin”, AFRC “Africa”, MEX “Mexico”, SEUS "South Eastern United States", SWUS "South Western United States". The contours represent the topography over the region of study with ERA-Interim data.

\section{Results}

\subsection{Precipitable water climatology}

Figure 2 shows the seasonal spatial distribution of atmospheric moisture originated from the Caribbean Sea (CARB) and the Tropical North Pacific (TNP). In this figure, the transport of atmospheric humidity is strongly driven by the VIMF field, and this in turn responds to the intensity of the LLJs, generating a very marked seasonality in the transport of atmospheric moisture over the region. The water vapor transported from both oceans to CAM shows a differential behavior over the region throughout the year. CARB provides an important contribution to the Central American east coast during December-January-February (DJF) and March-April-May (MAM) seasons. During June-July-August (JJA), with the increase of meridional component of the winds associated with CLLJ [3], there is a decrease in the contribution towards this coast, with increases towards the northern region (GoM). In the case of TNP, it is observed that the largest contributions to CAM coincide with the periods of maximum intensity of the $\mathrm{CJ}$ (boreal summer and fall), presenting its greatest contribution during the September-October-November (SON) season, when the southwesterly winds reach their maximum intensity. Figure 2 also shows the contrasting behavior between the CARB and TNP sources during the first two seasons of the year (DJF and MAM), as CARB has its greatest contribution associated with an increase in the intensity of the easterly winds during DJF that inhibit the strengthening southwesterly winds, which are crucial for the transport of moisture from the TNP.

The mean annual cycles of atmospheric moisture transport estimated by DRM, from the sources identified as major contributors to CAM, are shown in Figure 3. In this figure, it is evident that throughout the year the largest contributor of atmospheric moisture to the region is the Caribbean (CARB). Moisture from CARB is maximum during the winter and spring, and a minimum contribution during June. The latter could be associated to the period of maximum intensity of the CLLJ, which induces a greater transport of atmospheric moisture towards 
The 1st International Electronic Conference on Hydrological Cycle (CHyCle-2017), 12 - 16 November 2017 ; Sciforum Electronic Conference Series, Vol. 1, 2017

the Gulf of Mexico (see Figure 2). On the other hand, the contribution from the TNP (Figure 3) exhibits a bimodal cycle with maxima in June and September, periods that coincide with the seasons of greatest intensity of the CJ.
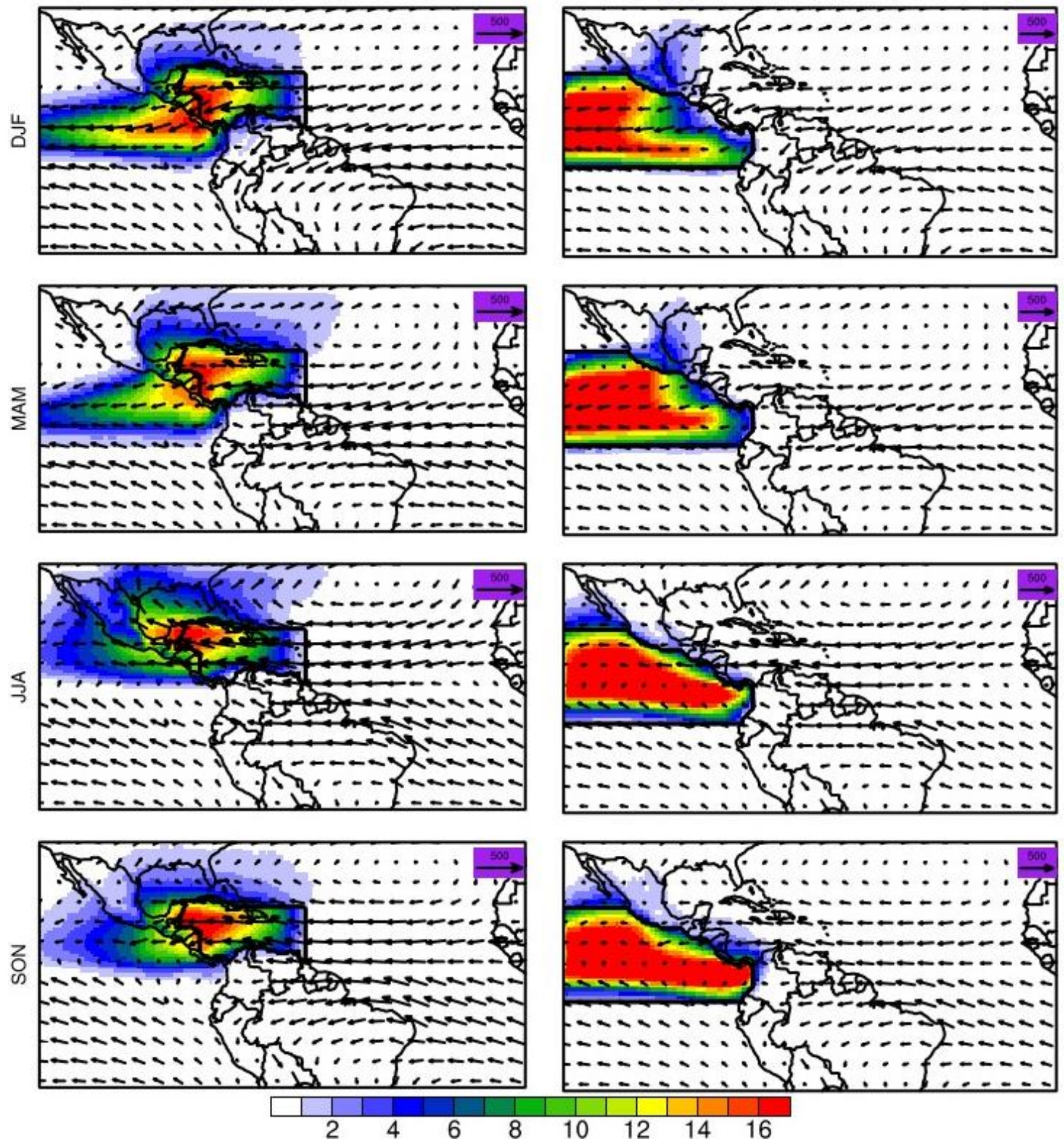

Figure 2. Seasonal patterns of precipitable water (mm) for 1980-2012 (shaded contours) originated from CARB (left) and from TNP (right) and VIMF (Vectors). 
The 1st International Electronic Conference on Hydrological Cycle (CHyCle-2017), 12 - 16 November 2017; Sciforum Electronic Conference Series, Vol. 1, 2017

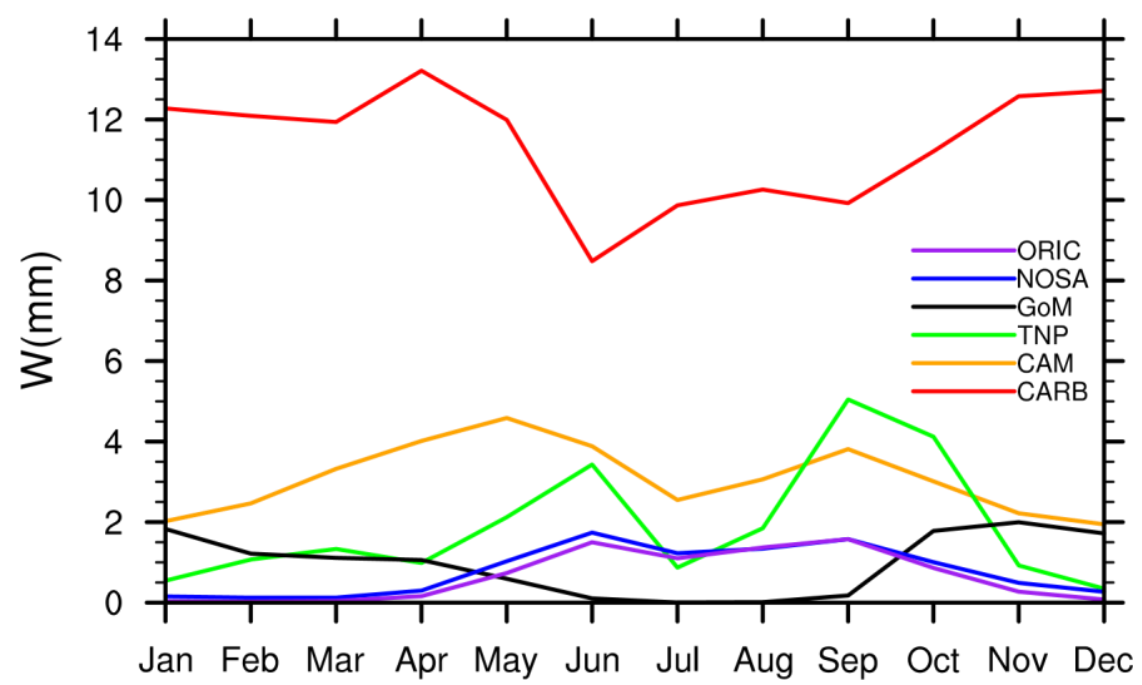

Figure 3. Mean annual cycle of contributions to precipitable water (W) over the CAM form the main sources (CARB, CAM, TNP, GoM, NOSA and ORIC).

On the other hand, moisture supply from the Gulf of Mexico (GoM) presents its biggest contribution from October to April. Afterwards, the transport of humidity from the area shows an abrupt decline until reaching almost zero contributions in July and August. During these last two months, the CLLJ is maximum, inducing an increase in atmospheric moisture transport towards the Central and Eastern United States, when interacting with the Great Plains low-level jet [14]. The dynamics of these jets inhibits the transport of water vapor from the GoM to CAM, given the predominance of southerly winds during its development. Furthermore, it is worth noting that although the humidity contribution of the GoM to CAM is much lower than that of the other oceanic sources already mentioned, GoM is an important source during the transition period from the wet to the dry season (DJF) and during the dry season.

Other important sources of humidity are Northern South America (NOSA) and CAM itself (i.e., recycling). The contributions from these continental sources to CAM are smaller than the contributions from most oceanic sources discussed so far. However, the exports of atmospheric moisture from CAM and NOSA to CAM still have an impact on the climate of the region. Between these two sources, NOSA is the one that presents the lowest contribution of water vapor, but its importance is seen in that its greatest contribution occurs during the boreal summer, a period that coincides with one of the periods of decline in the amount of moisture transported to CAM during the year, not to mention the mid-summer drought (MSD) that strongly affects the region during July and August [16]. Moisture recycling in CAM has an annual bimodal cycle, with maximum contributions during May and September. The DRM estimates of recycling are larger during the second half of the year compared to the FLEXPART estimates of Durán-Quesada et al. (2017).

\subsection{Interannual variability associated to Caribbean low-level jet and the Choco jet}

In order to analyze the interannual variations associated with these jets, in this section we analyze the correlations between the ICLLJ and the anomalies in the transport of atmospheric moisture from the Atlantic and from the CARB during August, when the transition from strong CLLJ to strong CJ takes place. We also present a similar analysis of correlations between the ICJ and moisture transport anomalies from the TNP and the Atlantic during October, when the $\mathrm{CJ}$ is stronger (Figure 4). In Figure 4a, positive correlations are observed over the entire CAM polygon, suggesting that an anomalously more intense jet (CLLJ) induces a larger moisture transport from the Atlantic towards Central America, besides inducing a drainage of humidity over the Antilles, represented with warm contours over this region. Figure 4c shows that the contribution from the Caribbean to Central America 
The 1st International Electronic Conference on Hydrological Cycle (CHyCle-2017), 12 - 16 November 2017;

Sciforum Electronic Conference Series, Vol. 1, 2017

and the TNP is larger when the CLLJ is stronger (positive correlation over Central America and the Eastern Pacific), while the recycling over the Caribbean is reduced (negative correlation over the Caribbean).

Figure $4 \mathrm{~b}$ suggests that an anomalously strong CJ inhibits transport from the Atlantic to the Pacific, CAM and southeastern Colombia (negative correlations), while inducing an increase in moisture recycling over the Atlantic during October (positive correlations). In contrast to this behavior, the signals in Figure $4 \mathrm{~d}$ show that an anomalously strong CJ generates greater moisture transport from TNP to CAM, CARB and southwestern Colombia.

August

a)

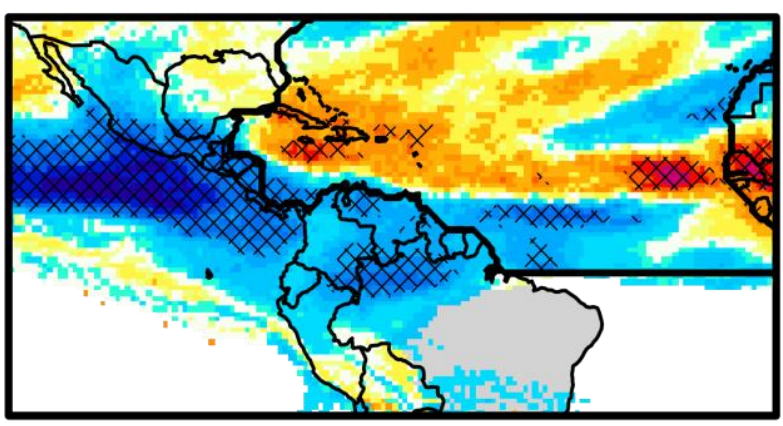

b)

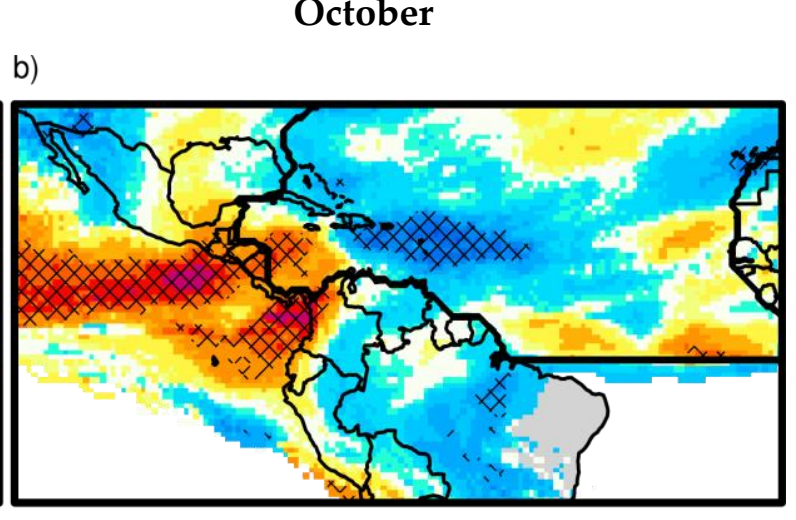

c)

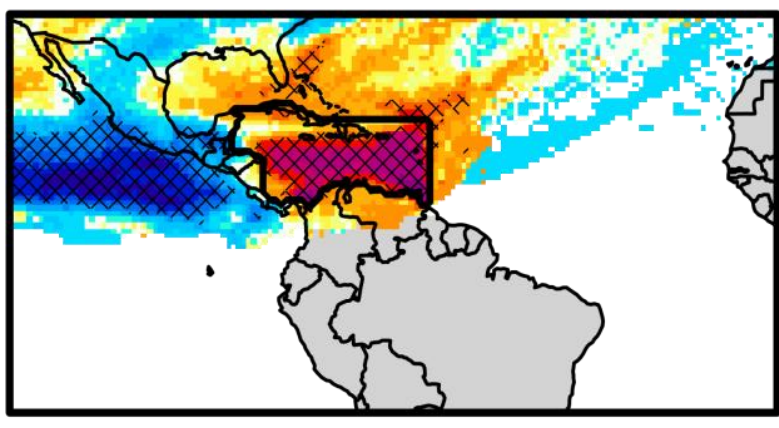

d)

\section{October}

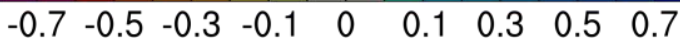

Figure 4. Correlation between the ICLLJ and moisture transport from Atlantic (a) and CARB (c) for August. Correlation between the ICJ and moisture transport from Atlantic (b) and TNP (d) for October. The hatching shows significant correlation with a p-value $<0.05$. In this case Atlantic region is the sum of CARB, TNA and NATL.

\subsection{Interannual variability associated to ENSO}

To study the influence of ENSO on the transport of atmospheric moisture in the region, we computed the differences in the transport of moisture from different sources between the warm and cold ENSO phases. The Oceanic Niño Index was used to classify each year as El Niño, Neutral or La Niña. Figure 5 shows the resulting differences of composites for August before (left column) and after (right column) the peak of each ENSO phase, and for December (middle column), during its peak. In this figure, it is observed that transport from the Atlantic to CAM and TNP presents a significant increase during August before the peak (ABP) of the warm phase of the ENSO. During this same period (ABP) and phase of the phenomenon there is a decrease of recycling moisture over different regions of the Atlantic such as the Antilles (reddish contours), associated with the strengthening of the CLLJ during the boreal summer during the warm phase of the ENSO [14]. 

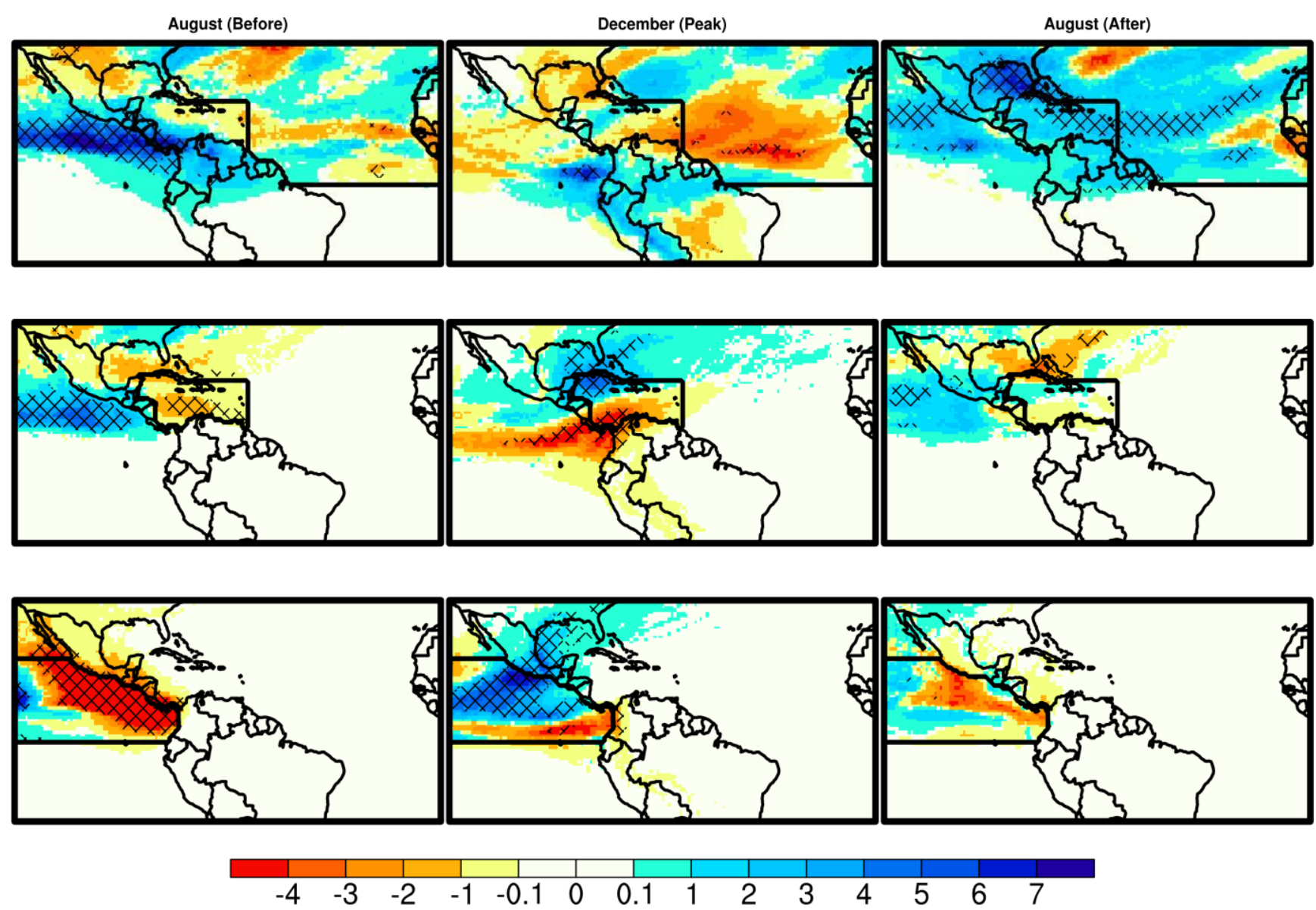

Figure 5. Composites of differences in moisture transport ( $\mathrm{mm}$ ) to CAM during El Niño and La Niña: from the Atlantic (top), the Caribbean (middle) and the TNP (lower panel). Blue (Red) colors represent an increase (decrease) in transport of moisture from each source during El Niño. The hatching shows significant differences with a p-value $<0.05$

In contrast, during the peak (December) of this same phase of the ENSO, the easterly winds are weaker, generating a drastic reduction of atmospheric moisture transport from the Atlantic to CAM. Additionally, there is a strengthening of moisture drainage over the Atlantic (reddish colors, top-middle panel) and a significant increase in humidity transported to the east Pacific coast of Colombia. During the August after the peak of the ENSO (AAP) there is a decrease in humidity transported to CAM and TNP from Atlantic during the warm phase of the ENSO. At this time, there is also an increase in the recycling of moisture in the Atlantic and in the transport to GoM during the same phase of the ENSO. This increase in recycling is suggested by the band of significant blue colors over the Atlantic during AAP. Because of the orientation and time of this blue pattern, it would be interesting to see if it can be related to the passage of tropical cyclones, which is beyond the scope of the present study.

For CARB and TNP, noticeable differences between the periods ABP and AAP are also observed. During El Niño, there is less transport of moisture from CARB to CAM during AAP compared to ABP. This is in contrast with what is observed for TNP, with an increase in transport to CAM during AAP. During the peak of the event (see December) it is evident the formation of a dipole over CARB associated with the strengthening of anomalous VIMF from NOSA to GoM (Figure A1). A similar behavior is presented for TNP, where a dipole is also observed associated with an increase in the recycling of humidity and the transport of moisture to CAM and Mexico, and a significant reduction over western Colombia and near the equator. This pattern suggests a shift in the destination of the moisture, from western Colombia to CAM and Mexico. 
The 1st International Electronic Conference on Hydrological Cycle (CHyCle-2017), 12 - 16 November 2017; Sciforum Electronic Conference Series, Vol. 1, 2017

a)

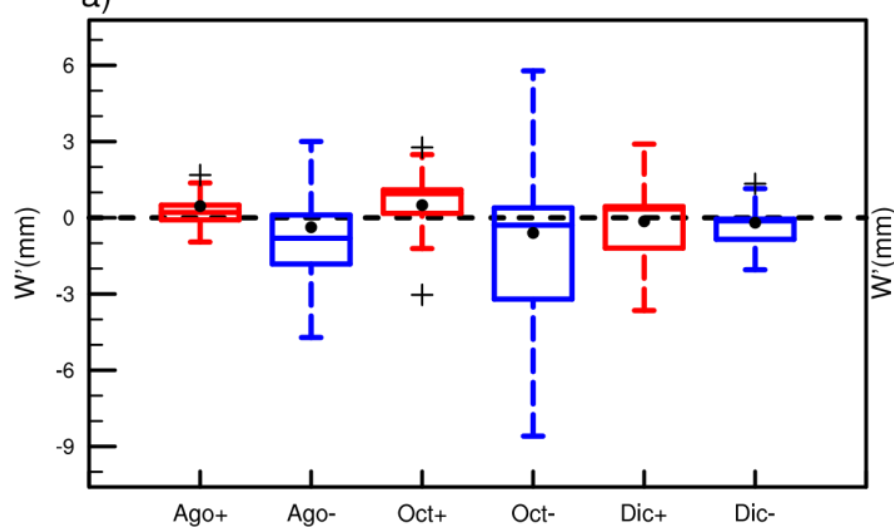

b)

TNP

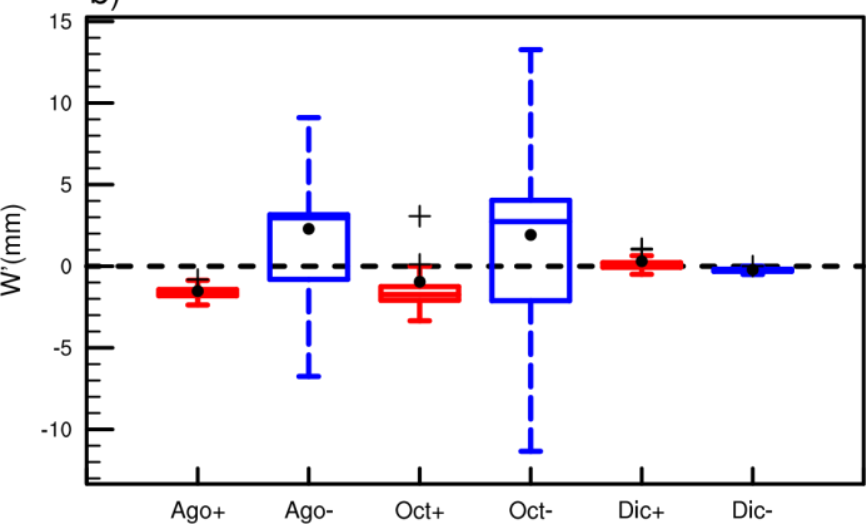

Figure 6. Composites of anomalies of the contribution to monthly precipitable water ( $\mathrm{mm}$ ) over the CAM by CARB (left) and TNP (right) during the extreme phases of ENSO. The plus (minus) sign denotes the positive (negative) phase of ENSO. The points represent the mean value for each distribution. The positive whisker extends from $q_{0.75}$ to $q_{0.25}+1.5\left(q_{0.75}-q_{0.25}\right)$ and the negative whisker extends from $q_{0.25}-1.5\left(q_{0.75}-q_{0.25}\right)$ to $q_{0.25}$, where $q_{0.25}$ and $q_{0.75}$ are the 25th and 75th percentiles, respectively.

Finally, we estimated the average contribution from TNP and CARB to CAM during the warm and cold phases of ENSO. Figure 6 shows the anomalous contributions for the El Niño (plus sign) and La Niña (minus sign) composites, during August (transition from CLLJ maximum to CJ maximum), October (maximum of CJ) and December (Peak of the ENSO). In this figure, it is evident that there is more variability during La Niña phase, and this variability is larger for the transport of moisture from the TNP compared to CARB, despite the fact the mean contribution from CARB is larger (see Figure 3). Likewise, a contrasting behavior is observed between the transport from these two sources during La Niña, given that the distribution associated with TNP for both months (August and October) suggests an increase in the transport to CAM, while there is a decrease in the moisture transported from CARB to CAM. During El Niño nearly the opposite happens, suggesting a noticeable increase in transport from CARB and a decrease from TNP. Conversely for December, there are greater variations for transport from CARB than for transport from TNP, with distributions that are wider during El Niño than during La Niña.

\section{Discussion}

The limitations of 2D models such as the DRM to represent the transport of moisture in regions with high values of the vertical shear of moisture flux (VSMF) were evident in this study, after performing a comparison with the results obtained by Durán-Quesada et al. (2017), who used the 3D FLEXPART model. In regions such as GoM, TNP and NOSA, which present low values of VSMF (Figure 7), we found consistency between the 2D-DRM and the 3D-FLEXPART for the moisture transport climatology. This is in contrast with the results for CAM and CARB, regions with high values of VSMF (Figure 7). In the case of CAM (i.e. recycling), the DRM estimates a bimodal annual cycle with peaks in May and September, while FLEXPART estimates a unimodal annual cycle, with the peak during April. These differences could be associated to the assumptions present in the 2D model, and its problems with regions of strong vertical wind shear. During July the CLLJ is very strong, inducing a strong shear in the transport of moisture, but also large values of VIMF in the dominant direction west-east. Thus, due to the high westerly VIMF in the middle of the year, derived from the CLLJ, the DRM estimates a reduction in moisture recycling in CAM (in other words, the moisture of local origin is taken away by the strong westerly VIMF). When the CLLJ weakens, after August, the recycling in CAM increases again. The contribution from CARB to CAM are likely to be affected by the CLLJ and resulting VIMF in the same way as the recycling in CAM just described. Issues with the DRM and regions of strong wind shear have been also reported in other studies [13,17]. 
The 1st International Electronic Conference on Hydrological Cycle (CHyCle-2017), 12 - 16 November 2017; Sciforum Electronic Conference Series, Vol. 1, 2017

Despite the limitations associated with the VSMF and the mean annual cycle of moisture transport from certain regions to CAM, in this study we found that the DRM is capable of capturing the signals associated with interannual variability, such as those related to the variability in the CLLJ, the CJ and the ENSO events. Our results are consistent with previous studies in terms of the interannual variability in atmospheric moisture transport associated with the low-level jets [14,18,19,1]. Furthermore, for the variability associated with ENSO, we found results in agreement with Durán-Quesada et al. [1]. It is interesting to note that that during El Niño, we found a weaker transport of atmospheric moisture over the Atlantic, as suggested by the contours in warm colors over the Atlantic during the ABP (Figure 5, top-left). This seems to be consistent with the fact that during El Niño there are less intense and less frequent hurricanes in the Atlantic (e.g. [20]), thus decreasing the poleward transport of moisture by this mechanism over the Atlantic.

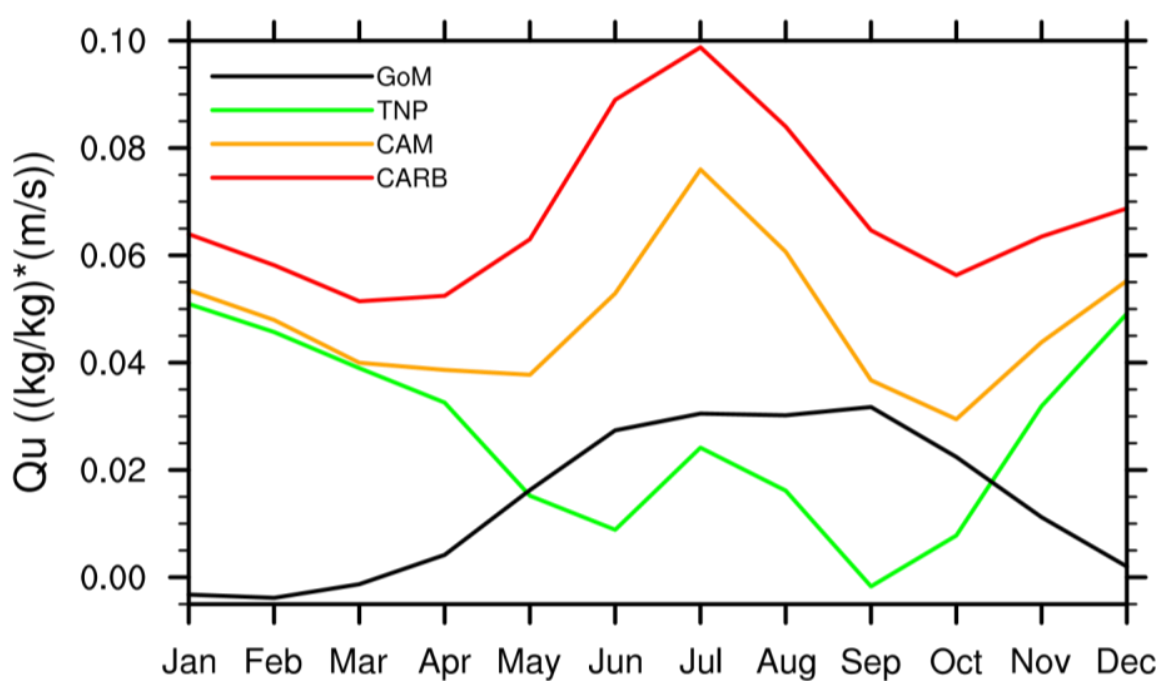

Figure 7. Mean annual cycle of vertical shear of moisture flux over the analyzed subregions (CARB, CAM, TNP y GoM)

\section{Conclusions}

In this study we used the semi-Lagrangian 2D model DRM to analyze the seasonal patterns of water vapor transport to Central America and its interannual variability associated with the Caribbean low-level jet (CLLJ), the Choco Jet (CJ) and the ENSO; for a period of 33 years from 1980 to 2012. The results obtained suggest that the largest contributor of mean annual atmospheric moisture transported to Central America is the Caribbean Sea, with an annual variation modulated by CLLJ dynamics. Additionally, moisture from sources such as northern South America and Gulf of Mexico is relevant for the region, given that their maximum contribution occurs when the transport of total moisture to Central America is in transition or is minimal. On the other hand, interannual variability associated with Low-Level Jets suggest that an anomalously strong (weak) CLLJ induces a higher (lower) transport from the Atlantic to Central America during August. And in the case of the CJ, there is a dipolar behavior between transport from Tropical North Pacific and Caribbean Sea, showing that an anomalously strong CJ induces a higher (lower) transport from the Pacific (Atlantic) to Central America during October. Likewise, the analysis for the ENSO, shows that the transport of moisture from the Atlantic, Caribbean Sea and Tropical North Pacific presents a high response to the annual cycle of evolution of the ENSO, which is evident in the change they present in the moisture transport patterns to Central America between the Augusts before and after the peak of the phenomenon for each of the regions.

Finally, it is important to mention that although the results obtained with DRM for climatological moisture transport from Caribbean Sea and Central America are biased by the development of the vertical shear of moisture flux, the model is able to capture the interannual variability associated to both the Low-Level Jets and the ENSO. Because of its simplicity and very low computational requirements, the DRM could be a useful tool to study 
The 1st International Electronic Conference on Hydrological Cycle (CHyCle-2017), 12 - 16 November 2017;

Sciforum Electronic Conference Series, Vol. 1, 2017

atmospheric moisture transport in large data sets and simulations. We are exploring this capability with CMIP5 simulations.

Acknowledgments: We acknowledge the ECMWF for providing the ERA-Interim data and the CPC for providing the ONI index data. We also acknowledge Francina Domínguez, from the Department of Atmospheric Sciences of the University of Illinois who developed the DRM and provided the original source code. This research was supported by Universidad de Antioquia.

Author Contributions: Jose S. Morales made the calculations and analyzed the data. Paola A. Arias and J. Alejandro Martinez conceived and designed the main research ideas and methods. Morales, Arias and Martinez worked on the main discussions and conclusions. Jose S. Morales wrote the paper.

Conflicts of Interest: The authors declare that they have no conflict of interest.

\author{
Abbreviations \\ The following abbreviations are used in this manuscript: \\ DRM: Dynamic Recycling Model \\ CAM: Central America \\ CLLJ: Caribbean low-level jet \\ $\mathrm{CJ}$ : Choco jet \\ ENSO: El Niño-Southern Oscillation \\ VIMF: Vertical integrated moisture flux \\ ICLLJ: Caribbean jet index \\ ICJ: Choco jet index \\ NOAA: National Oceanic And Atmospheric Administration \\ ONI: Oceanic Niño Index \\ CARB: Caribbean Sea \\ TNP: Tropical North Pacific \\ LLJs: Low-Level Jets \\ GoM: Gulf of Mexico \\ NOSA: Northern South America \\ MSD: Mid-Summer Drought \\ ABP: August before the peak of ENSO \\ AAP: August after the peak of ENSO \\ VSMF: Vertical Shear of Moisture Flux
}

\title{
References
}

1. Durán-Quesada, A. M., Gimeno, L., \& Amador, J. (2017). Role of moisture transport for Central American precipitation. Earth System Dynamics, 8(1), 147.

2. Durán-Quesada, A. M., Gimeno, L., Amador, J. A., and Nieto, R. (2010). Moisture sources for Central America: Identification of moisture sources using a Lagrangian analysis technique, J. Geophys. Res.- Atmos., 115, D05103, doi:10.1029/2009JD012455

3. Amador, J. A. (2008). The Intra-Americas Sea Low-level Jet. Annals of the New York Academy of Sciences, 1146(1), $153-188$. https://doi.org/10.1196/annals.1446.012

4. Poveda, G., Jaramillo, L., \& Vallejo, L. F. (2014). Seasonal precipitation patterns along pathways of South American lowlevel jets and aerial rivers. Water Resources Research, 50(1), 98-118. https://doi.org/10.1002/2013WR014087

5. Taylor, M. A. and Alfaro, E. J.: Central America and the Caribbean, in: Encyclopedia of world climatology, Springer Netherlands, 183-189, 2005.

6. Van der Zee Arias, A., Alain Van der Zee, J., Meyrat, A., Poveda, C. \& Picado, L. (2012). Estudio de caracterizacion del Corredor Seco Centroamericano (No. 630.2515/V217e). FAO.

7. Domínguez, F., Kumar, P., Liang, X. Z., \& Ting, M. (2006). Impact of atmospheric moisture storage on precipitation recycling. Journal of Climate, 19(8), 1513-1530. https://doi.org/10.1175/ICLI3691.1 
The 1st International Electronic Conference on Hydrological Cycle (CHyCle-2017), 12 - 16 November 2017;

Sciforum Electronic Conference Series, Vol. 1, 2017

8. Martinez, J. A., \& Domínguez, F. (2014). Sources of Atmospheric Moisture for the La Plata River Basin*. Journal of Climate, 27(17), 6737-6753. https://doi.org/10.1175//CLI-D-14-00022.1

9. Dee, D. P., Uppala, S. M., Simmons, A. J., Berrisford, P., Poli, P., Kobayashi, S., ... \& Bechtold, P. (2011). The ERA-Interim reanalysis: Configuration and performance of the data assimilation system. Quarterly Journal of the royal meteorological society, 137(656), 553-597.

10. Agudelo, J., Arias, P.A., Vieira, S.C., and Martinez, J. A. (2017). The lengthening of the Amazon dry season: influence on water vapor transport toward the Intra-American region. Climate Dynamics, under review.

11. Goessling HF, Reick CH (2013) On the "well-mixed" assumption and numerical 2-D tracking of atmospheric moisture. Atmos Chem Phys 13:5567-5585. doi:10.5194/acp-13-5567-2013

12. Van der Ent RJ, Tuinenburg OA, Knoche HR, Kunstmann H, Savenije HHG (2013) Should we use a simple or complex model for moisture recycling and atmospheric moisture tracking? Hydrol Earth Syst Sci 17:4869-4884. doi:10.5194/hess17-4869-2013

13. Hu, H., \& Dominguez, F. (2015). Evaluation of Oceanic and Terrestrial Sources of Moisture for the North American Monsoon Using Numerical Models and Precipitation Stable Isotopes. Journal of Hydrometeorology, 16(1), $19-35$. https://doi.org/10.1175/JHM-D-14-0073.1

14. Wang, C. (2007). Variability of the Caribbean Low-Level Jet and its relations to climate. Climate Dynamics, 29(4), 411-422. https://doi.org/10.1007/s00382-007-0243-z

15. Poveda G, Mesa OJ (2000) On the existence of Lloró (the rainiest locality on Earth): enhanced ocean-atmosphere-land interaction by a low level jet. Geophys Res Lett 27:1675-1678

16. Magaña, V., Amador, J. A., \& Medina, S. (1999). The midsummer drought over Mexico and Central America. Journal of Climate, 12(6), 1577-1588. https://doi.org/10.1175/1520-0442(1999)012<1577:tmdoma>2.0.co;2

17. Dominguez, F., Miguez-Macho, G., \& Hu, H. (2016). WRF with Water Vapor Tracers: A Study of Moisture Sources for the North American Monsoon. Journal of Hydrometeorology, 17(7), 1915-1927. https://doi.org/10.1175/JHM-D-15-0221.1

18. Muñoz, E., A. J. Busalacchi, S. Nigam, and A. Ruiz-Barradas, 2008: Winter and summer structure of the Caribbean lowlevel jet. J. Climate, 21, 1260-1276

19. Cook, K. H., \& Vizy, E. K. (2010). Hydrodynamics of the Caribbean low-level jet and its relationship to precipitation. Journal of Climate, 23(6), 1477-1494.

20. Lupo, A. R., \& Johnston, G. (2000). The variability in Atlantic Ocean Basin hurricane occurrence and intensity as related to ENSO and the North Pacific Oscillation.

(C) 2017 by the authors; licensee MDPI, Basel, Switzerland. This article is an open access article distributed under the terms and conditions of the Creative Commons by Attribution (CC-BY) license (http://creativecommons.org/licenses/by/4.0/). 
The 1st International Electronic Conference on Hydrological Cycle (CHyCle-2017), 12 - 16 November 2017; Sciforum Electronic Conference Series, Vol. 1, 2017

Appendix A

August (Before)

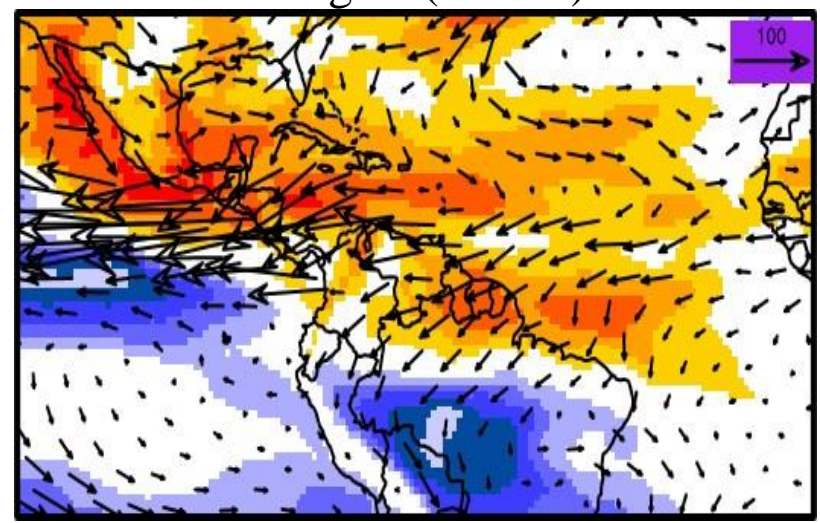

December (Peak)

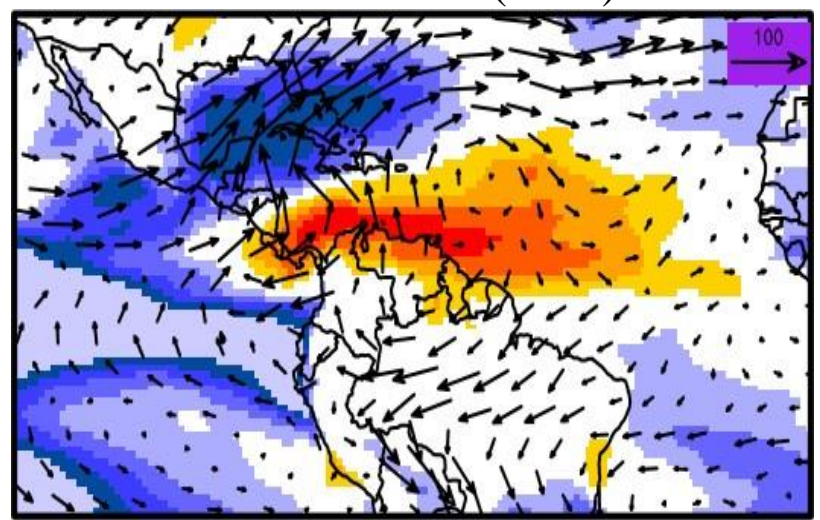

August (After)

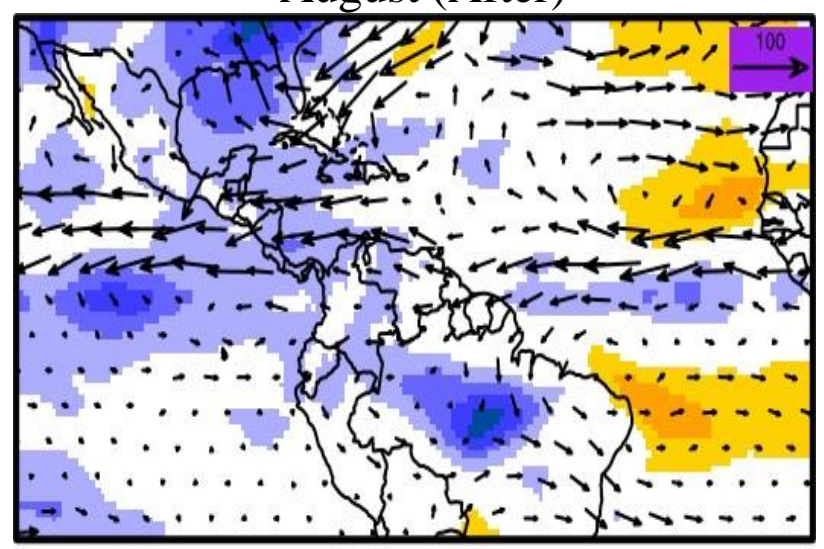

$\begin{array}{llllllllllll}-4 & -3 & -2 & -1 & 0 & 1 & 2 & 3 & 4 & 5\end{array}$

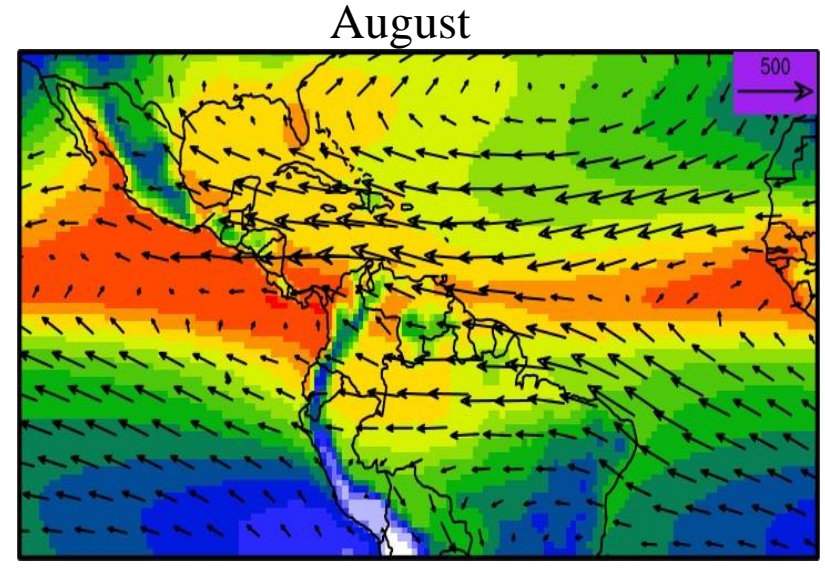

December

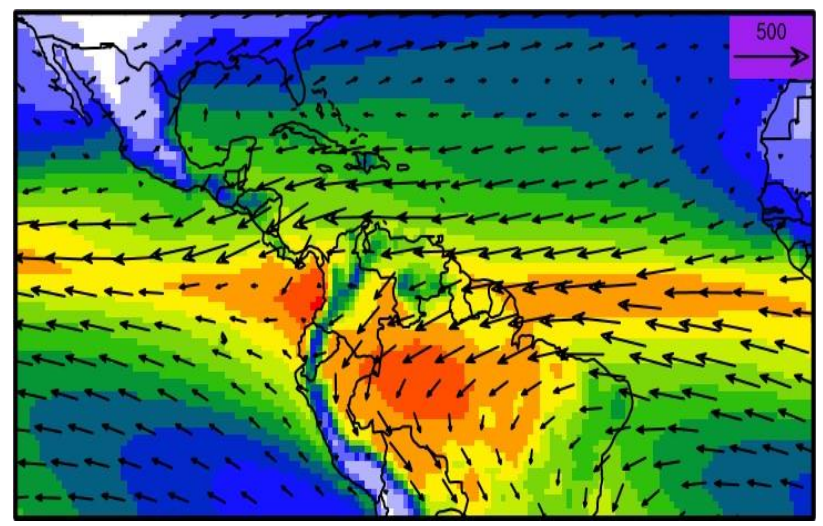

$4 \quad 8 \quad 12 \quad 16 \quad 20 \quad 242832 \quad 36 \quad 40 \quad 44 \quad 48 \quad 52 \quad 56$

Figure A1. Composites of differences in VIMF (Vectors) and W (shaded contours, mm) during El Niño and La Niña (Left column) for the same months in Figure 5. Climatology of VIMF and W (mm) for 1980-2012 during August and December, including El Niño, La Niña and neutral years (right column). 